\title{
Effective Metabolic Targeting of Human Osteosarcoma Cells In Vitro and in Orthotopic Nude-mouse Models with Recombinant Methioninase
}

\author{
KENTARO IGARASHI ${ }^{1,2,3}$, KEI KAWAGUCHI ${ }^{1,2}$, TASUKU KIYUNA ${ }^{1,2}$, KENTARO MIYAKE $^{1,2}$, \\ TAKASHI MURAKAMI ${ }^{1,2}$, NORIO YAMAMOTO ${ }^{3}$, KATSUHIRO HAYASHI $^{3}$, \\ HIROAKI KIMURA ${ }^{3}$, SHINJI MIWA ${ }^{3}$, HIROYUKI TSUCHIYA ${ }^{3}$ and ROBERT M. HOFFMAN ${ }^{1,2}$ \\ ${ }^{1}$ AntiCancer, Inc., San Diego, CA, U.S.A.; \\ ${ }^{2}$ Department of Surgery, University of California, San Diego, CA, U.S.A.; \\ ${ }^{3}$ Department of Orthopaedic Surgery, Kanazawa University, Kanazawa, Japan
}

\begin{abstract}
Background: Methionine dependence may be the only known general metabolic defect in cancer. In order to exploit methionine dependence for therapy, our laboratory previously cloned L-methionine $\alpha$-deamino- $\gamma$-mercaptomethane lyase [EC 4.4.1.11]) (recombinant methioninase [rMETase]), which was subsequently tested in mouse models of various types of human tumors. The present study aimed to investigate the efficacy of rMETase on human osteosarcoma cells in vitro and in vivo. Materials and Methods: Human osteosarcoma cell lines $143 B, H O S$ and SOSN2 were tested in vitro for survival during a 72-h exposure to rMETase using the WST-8 assay. Halfmaximal inhibitory concentrations were calculated for in vitro efficacy experiments. $143 B$ cells were orthotopically transplanted into the tibia of nude mice. Mouse models were randomized into the following groups 1 week after transplantation: Group 1, untreated control; Group 2, cisplatinum (CDDP) [intraperitoneal (i.p.) injection at 6 $\mathrm{mg} / \mathrm{kg}$ weekly, for 3 weeks], positive control; Group 3, rMETase, 100 units/mouse i.p. daily, for 21 days. Tumor sizes and body weight were measured with calipers and a digital balance once per week, respectively. Results: rMETase significantly inhibited osteosarcoma cell growth, in a dose-dependent manner, in vitro. Both CDDP and rMETase
\end{abstract}

Correspondence to: Robert M. Hoffman, Ph.D., AntiCancer, Inc., 7917 Ostrow Street, San Diego, CA 92111, U.S.A. Tel: +1 8586542555, Fax: +18582684175, e-mail: all@anticancer.com or Hiroyuki Tsuchiya, MD, Ph.D., Dept. of Orthopaedic Surgery, Graduate School of Medicine, Kanazawa University, 13-1 Takaramachi, Kanazawa 920-8641, Japan. Tel: +81 762652374, Fax: +81 762344261,e-mail: tsuchi@med.kanazawa-u.ac.jp

Key Words: Metabolic targeting, osteosarcoma, recombinant methioninase, rMETase, treatment, in vitro, orthotopic, nude mice, efficacy. treatment significantly inhibited tumor volume compared to untreated control mice at 5 weeks after initiation. Tumor volumes were as follows: Group 1, untreated, control: 1808.2 $\pm 344 \mathrm{~mm}^{3}$; Group 2, CDDP: $1102.2 \pm 316 \mathrm{~mm}^{3}, p=0.0008$ compared to untreated control; Group 3, rMETase: $884.8 \pm$ $361 \mathrm{~mm}^{3}, p=0.0001$ compared to untreated control. There were no animal deaths in any group. The body weight of mice was not significantly different between any group. Conclusion: rMETase showed promising efficacy against osteosarcoma, a recalcitrant tumor type. Future studies will investigate the efficacy of rMETase on patient-derived orthotopic xenograft (PDOX) models of osteosarcoma as a bridge to testing rMETase in the clinic.

Methionine (MET) dependence may be the only known general and very widespread metabolic defect in cancer (1). Numerous cell types have been shown to arrest their growth when deprived of MET (2-6). Malignant human cell lines were able to synthesize MET from homocysteine at rates that were at least as high as normal human skin fibroblast strains (7). These data suggest that MET dependence may be caused by an altered and enhanced utilization of MET as opposed to an inability to synthesize MET from homocysteine (7). Methionine deprivation causes cancer cells to arrest predominantly in the $S / G_{2}$ phases of the cell cycle and to eventually undergo apoptosis (6-11).

We previously observed that cancer cells have enhanced overall rates of transmethylation compared to normal human fibroblasts (12). The overuse of methionine for enhanced and unbalanced transmethylation may be the basis of the methionine dependence of cancer cells. The overuse of methionine by cancer cells is termed the 'Hoffman effect' (13-15). The alteration of such a fundamental process as transmethylation in cancer may be indicative of its importance in the oncogenic process (12-14). 
Methionine depletion can be achieved using recombinant Lmethioninedeamino- $\gamma$ - mercaptomethane-lyase [EC 4.4.1.11] (recombinant methioninase [rMETase], a methionine-cleaving enzyme derived from Pseudomonas putida) (16). Our laboratory previously cloned and expressed rMETase in Escherichia coli (17).

Previously, 21 different human cancer cell lines (four each of lung, colon, kidney, and melanoma, three from CNS, and two from prostate) and normal cell strains were treated with rMETase in vitro. rMETase had a mean half-maximal inhibitory concentration $\left(\mathrm{IC}_{50}\right)$ for cancer cells which was one order of magnitude lower than that for normal cell strains (4).

rMETase arrested growth of HCT 15 and HT29 colon cancer in nude mice for 1 week after treatment termination. Growth of Colo 205 and SW 620 colon cancers were partially arrested by rMETase (18). Methionine dependence was also found to occur in fresh patient tumors histocultured on Gelfoam ${ }^{\circledR}(5,6)$. rMETase also arrested growth of a Ewing's sarcoma patientderived orthotopic xenograft (PDOX) mouse model (15).

Osteosarcoma is a common malignant primary bone tumor occurring in patients aged 10-25 years. Osteosarcoma has a 5year survival rate of approximately $70 \%$ in patients treated with chemotherapy and surgery. However, the survival rate is much lower after metastasis has occurred (19-21). The most effective chemotherapeutic drugs against osteosarcoma are high-dose methotrexate, cisplatinum, doxorubicin, and ifosfamide. However, dose escalation of these drugs did not improve the outcome of osteosarcoma patients (22). Since the survival of patients with osteosarcoma has plateaued, transformational new treatment approaches are needed.

In the present study, we evaluated the efficacy of rMETase on human osteosarcoma cell lines in vitro and in vivo in an orthotopic mouse model as a potential treatment for clinical osteosarcoma in the future.

\section{Materials and Methods}

Cell lines and growth conditions. The following human osteosarcoma cell lines were used: 143B, HOS and SOSN2 $(23,24)$. Cells were kept in log phase by supplementation with fresh medium 2-3 times/week. All cells were grown in RPMI-1640 medium supplemented with $10 \%$ fetal bovine serum, $100 \mathrm{U} / \mathrm{ml}$ penicillin, and $100 \mu \mathrm{g} / \mathrm{ml}$ streptomycin.

Growth-inhibition assay. Cell viability was assessed using the WST8 dye reduction assay. Briefly, cells were seeded in 96-well flatbottomed microplates $(100 \mu \mathrm{lmedium} /$ well $)$ at a density of $5 \times 10^{4}$ cells $/ \mathrm{ml}$, incubated at $37^{\circ} \mathrm{C}$ for $24 \mathrm{~h}$, and exposed to different concentrations of tested compounds for $72 \mathrm{~h}$. For each drug concentration, at least 8 wells were used. Before the WST- 8 assay was performed, cells were observed with the Power IX71 microscope (Olympus Corp., Tokyo, Japan) at $\times 200$ magnification. After incubation with rMETase, $10 \mu \mathrm{l}$ WST- 8 solution was added to each well. The microplates were further incubated for $3 \mathrm{~h}$ at $37^{\circ} \mathrm{C}$, and absorption was measured using a microprocessor-controlled

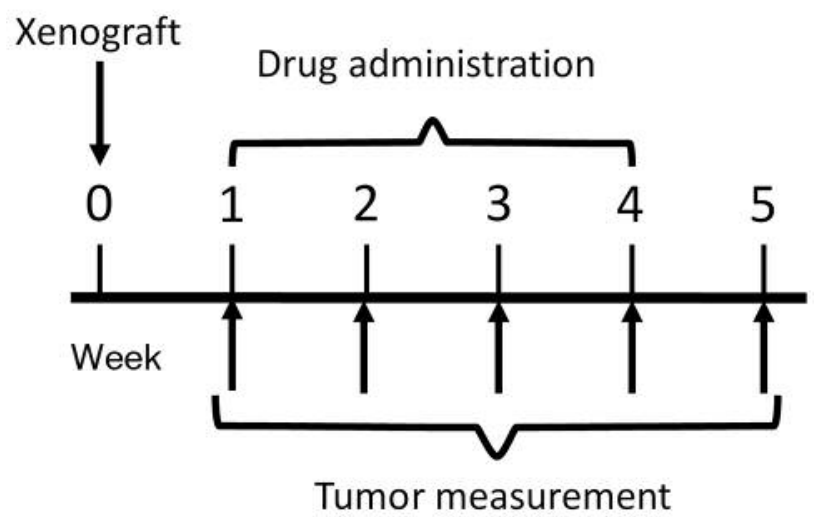

Figure 1. Treatment schema in mice.

microplate reader (iMark ${ }^{\mathrm{TM}}$; Bio-Rad Laboratories, Hercules, CA, USA) at $450 \mathrm{~nm}$. Cell-survival fractions were calculated as a percentage of untreated-control cells. Half-maximal inhibitory concentration $\left(\mathrm{IC}_{50}\right)$ values were derived from concentrationresponse curves.

Mice. Athymic nu/nu nude mice (AntiCancer Inc., San Diego, CA, USA), 4-6 weeks old, were used in this study. Animals were housed in a barrier facility on a high-efficiency particulate arrestancefiltered rack under standard conditions of 12-h light/dark cycles. The animals were fed an autoclaved laboratory rodent diet. All animal studies were conducted with an AntiCancer Institutional Animal Care and Use Committee protocol specifically approved for this study and in accordance with the principles and procedures outlined in the National Institute 5 of Health Guide for the Care and Use of Animals under Assurance Number A3873-1. In order to minimize any suffering of the animals, anesthesia and analgesics were used for all surgical experiments. The response of animals during surgery was monitored to ensure adequate depth of anesthesia. The animals were observed on a daily basis and humanely sacrificed by $\mathrm{CO}_{2}$ inhalation when they met the following humane endpoint criteria: severe tumor burden (more than $20 \mathrm{~mm}$ in diameter), prostration, significant-body weight loss, difficulty inbreathing, rotational motion and drop in body temperature (1).

Intra-tibial $143 B$ transplantation. The mice were anesthetized by subcutaneous injection of a ketamine mixture $(0.02 \mathrm{ml}$ solution of $20 \mathrm{mg} / \mathrm{kg}$ ketamine, $15.2 \mathrm{mg} / \mathrm{kg}$ xylazine and $0.48 \mathrm{mg} / \mathrm{kg}$ acepromazine maleate). A skin incision was made for tibial exposure. A pin hole was made in the proximal tibia. Then, a suspension of $143 \mathrm{~B}$ cells $\left(2 \times 10^{5}\right)$ in $10 \mu \mathrm{l}$ phosphate-buffered saline containing $5 \mu$ Matrigel $^{\mathrm{TM}}$ (Becton Dickinson, Bedford, MA, USA) to prevent the suspension from leaking out, was transplanted through the pinhole using a 23-gauge needle. Tumors were measured once weekly using digital calipers and weighed (24-27).

One week after transplantation, mouse models were randomized into the following groups $(n=8)$ : Group 1, control without treatment; Group 2, cisplatinum (CDDP): $6 \mathrm{mg} / \mathrm{kg}$, intraperitoneal (i.p.), weekly, for 3 weeks; Group 3, rMETase, 100 units/mouse i.p. daily, for 21 days (18). Tumor sizes and body weight were measured with calipers and digital balance, respectively, once a week (Figure 1). 

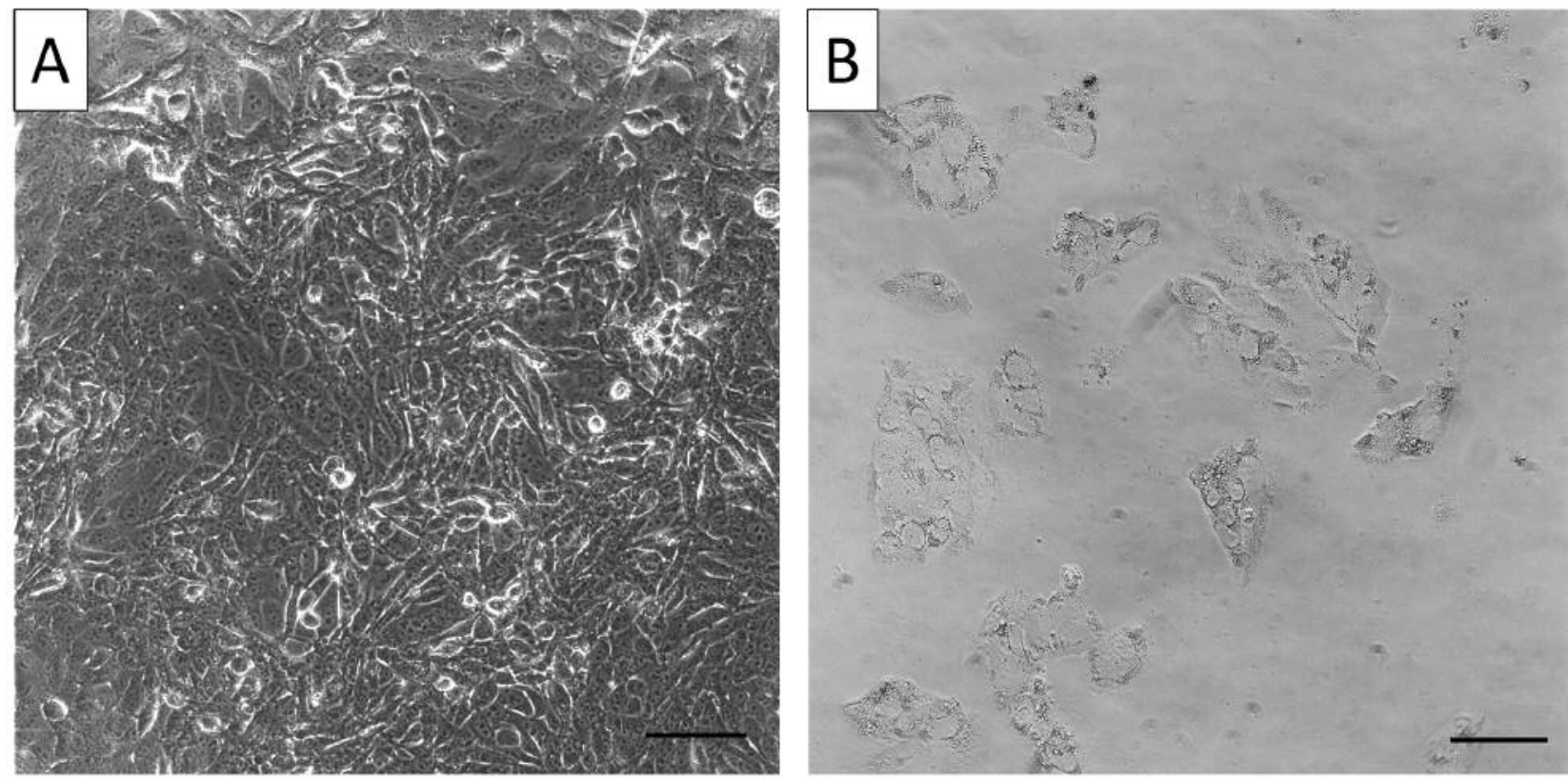

Figure 2. $143 B$ osteosarcoma cells $72 \mathrm{~h}$ after incubation without (A) and with (B) $1.25 \mathrm{U} / \mathrm{ml}$ recombinant L-methionine $\alpha$-deamino- $\gamma$ mercaptomethane lyase (recombinant methioninase [rMETase]). Scale bar: $100 \mu \mathrm{m}$.

Primary tumor growth measurement. The tumors were allowed to form and tumor dimensions were measured weekly. Tumor volumes were calculated using the following equation: volume $=4 \pi$ $(\mathrm{A} / 2)(\mathrm{B} / 2)(\mathrm{C} / 2) / 3$, where $\mathrm{A}$ is the width (average distance in the medial-lateral plane), $\mathrm{B}$ is the length (average distance in the proximal-distal plane), and $\mathrm{C}$ is the width (average distance in the anterior-posterior plane).

\section{Results and Discussion}

Cytotoxicity. The cytotoxic activity of rMETase was determined against 143B, HOS, and SOSN2 osteosarcoma cell lines, which were incubated for $72 \mathrm{~h}$ with rMETase or CDDP. Cell survival was evaluated as described in the Materials and Methods. rMETase significantly inhibited osteosarcoma cell growth in a dose-dependent manner (Figures 2 and 3, Table I). There was approximately a 7-fold range in the sensitivity of osteosarcoma cells, with 143B being the most sensitive and SOSN2 being the least sensitive.

Orthotopic mouse model. 143B cells were transplanted intratibially in nude mice. One week after transplantation, mice were treated with either rMETase or CDDP In both treatment groups, osteosarcoma growth was significantly inhibited compared to untreated controls. At 5 weeks after initiation of treatment, tumor volumes were as follows: control: $1808.2 \pm 344 \mathrm{~mm}^{3}$; CDDP: $1102.2 \pm 316 \mathrm{~mm}^{3}$, $p=0.0008$; rMETase: $884.8 \pm 361 \mathrm{~mm}^{3}, p=0.0001$ (Figure 4).
There were no animal deaths in any group. The body weight of mice was not significantly different in any group (Figure 5).

The first indication that methionine metabolism is perturbed in cancer was presented by Sugimura et al., almost 60 years ago, who observed that rat tumor growth was slowed by a diet depleted of methionine (28). Subsequently, L5178Y mouse leukemia cells in culture were observed to require very high levels of methionine in order to proliferate (29). Many cancer cell lines were then found to be methionine dependent, requiring high amounts of methionine in order to proliferate $(3,4)$. Tumors from human patients, including tumors of the colon, breast, ovary, prostate, and a melanoma, were also found to be methionine-dependent in Gelfoam ${ }^{\circledR}$ histoculture (5). The occurrence of methionine dependence among diverse cancer types indicates methionine dependence may be a general phenomena in cancer. In contrast, normal unestablished cell strains characterized grew well in methionine-depleted medium (3).

Methionine restriction selectively arrests cancer cells in the $S / G_{2}$ phases of the cell cycle $(6,8,10,11)$, which can be exploited for effective chemotherapy (9-11).

A recent article appeared in 2017 with the title "The new anticancer era: Tumor metabolism targeting" (30). However, this "new anticancer era" started in 1959 with the observation of Sugimura et al. that depriving cancer of methionine arrested tumor growth (28). The current results and previous reports demonstrate that targeting methionine 

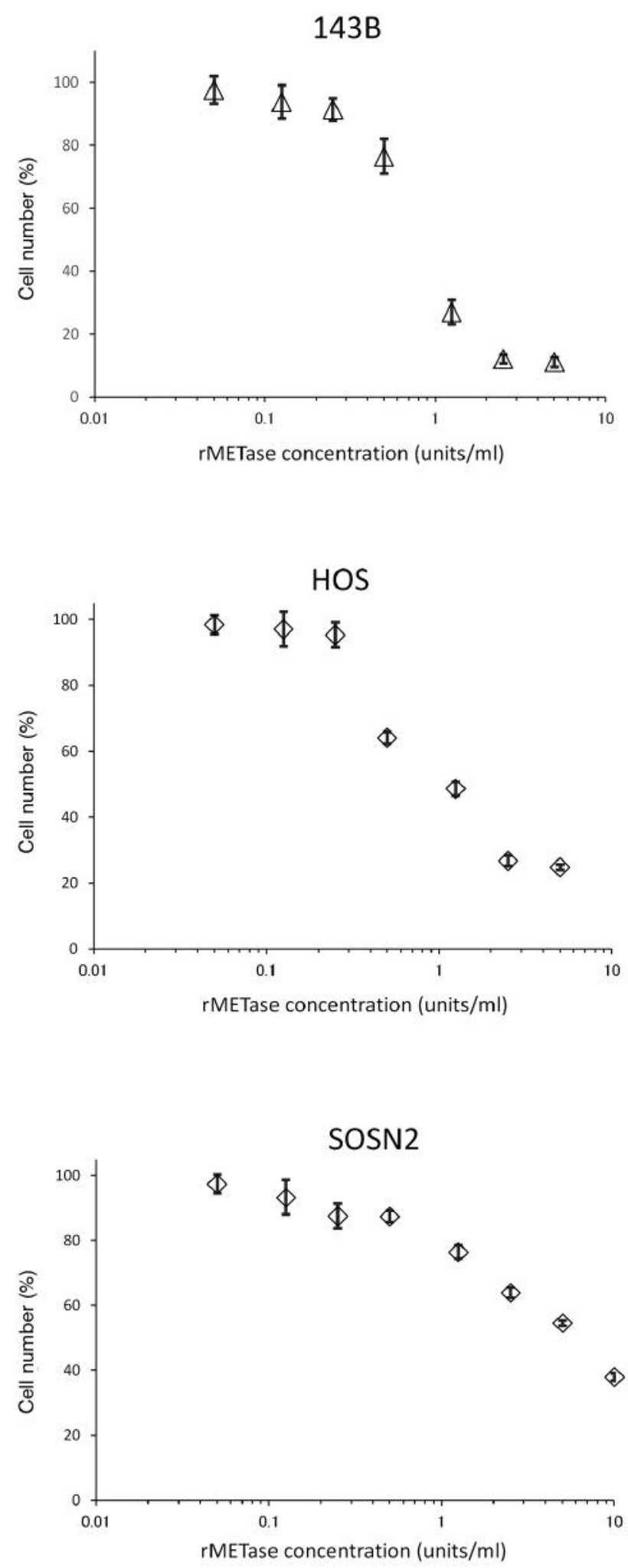

Figure 3. Effect of recombinant methioninase (rMETase) on viability of osteosarcoma cells. Osteosarcoma cells were incubated with rMETase for $72 h$ and then viability was measured with the WST-8 assay. Data are mean $\pm S D, n=$ replicates.

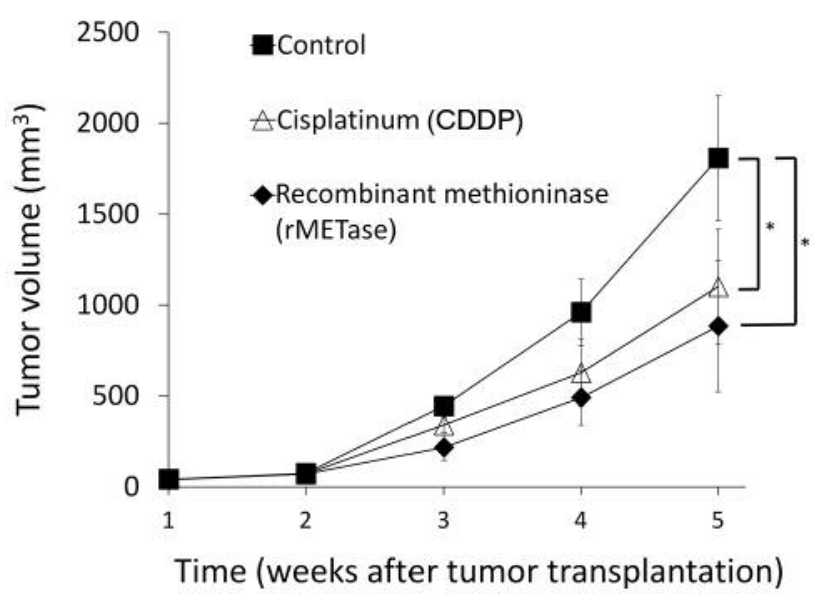

Figure 4. In vivo antitumor efficacy of CDDP and rMETase. $143 B$ human osteosarcoma cells were grown orthotopically in the left tibia of nude mice and allowed to form tumors. Mice were treated with CDDP $(6 \mathrm{mg} / \mathrm{kg} / \mathrm{week}$, i.p., for 3 weeks); or rMETase (100 units/mouse/day, i.p., daily for 21 days). Tumor volume was measured at the indicated time points after the onset of treatment. Data are mean $\pm S D, n=8$ mice/group. ${ }^{*} p<0.001$.

Table I. Half-maximal inhibitory concentrations $\left(I C_{50}\right)$ values (units/ml) for recombinant methioninase (rMETase) against osteosarcoma cell lines. Data are mean $\pm S D$.

\begin{tabular}{lc}
\hline Cell line & $\mathrm{IC}_{50}$ value (units $\left./ \mathrm{ml}\right)$ \\
\hline $143 \mathrm{~B}$ & $0.79 \pm 0.15$ \\
HOS & $1.06 \pm 0.09$ \\
SOSN2 & $5.67 \pm 1.02$ \\
\hline
\end{tabular}

metabolism has great potential for cancer therapy. Our current and previous (15) findings suggest an important future clinical target for rMETase in osteosarcoma.

\section{Dedication}

This article is dedicated to the memory of A. R. Moossa, M.D., and Sun Lee, M.D.

\section{References}

1 Hoffman RM: Development of recombinant methioninase to target the general cancer-specific metabolic defect of methionine dependence: a 40-year odyssey. Expert Opin Biol Ther 15: 21$31,2015$.

2 Hoffman RM: Altered methionine metabolism, DNA methylation and oncogene expression in carcinogenesis. A review and synthesis. Biochim Biophys Acta 738: 49-87, 1984.

3 Mecham JO, Rowitch D, Wallace CD, Stern PH and Hoffman RM: The metabolic defect of methionine dependence occurs frequently in human tumor cell lines. Biochem Biophys Res Commun 117: 429-434, 1983. 

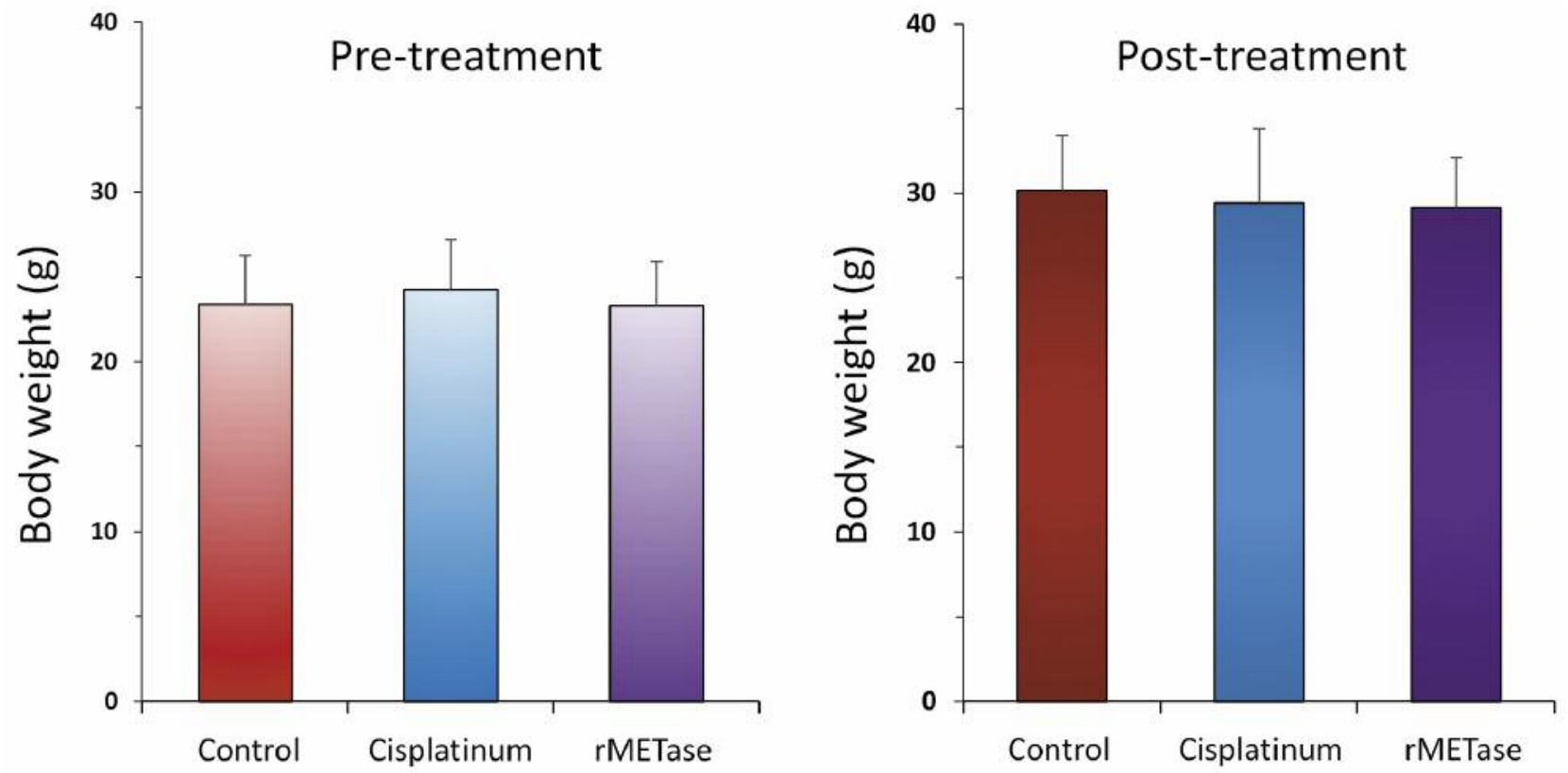

Figure 5. Effect of cisplatinum (CDDP) and L-methionine $\alpha$-deamino- $\gamma$-mercaptomethane lyase (recombinant methioninase [rMETase]) on mouse body weight. Data are mean $\pm S D$ body weight $(g)$ for each group at pre-treatment and 4 weeks after treatment initiation. There were no significant differences between groups.

4 Tan Y, Xu M and Hoffman RM: Broad selective efficacy of recombinant methioninase and polyethylene glycol-modified recombinant methioninase on cancer cells in vitro. Anticancer Res 30: 1041-1046, 2010.

5 Guo HY, Herrera H, Groce A and Hoffman RM: Expression of the biochemical defect of methionine dependence in fresh patient tumors in primary histoculture. Cancer Res 53: 2479-2483, 1993.

6 Guo H, Lishko V, Herrera H, Groce A, Kubota T and Hoffman RM: Therapeutic tumor-specific cell-cycle block induced by methionine starvation in vivo. Cancer Res 53: 5676-5679, 1993.

7 Hoffman RM and Erbe RW: High in vivo rates of methionine biosynthesis in transformed human and malignant rat cells auxotrophic for methionine. Proc Natl Acad Sci USA 73: 1523 $1527,1976$.

8 Hoffman RM and Jacobsen SJ: Reversible growth arrest in simian virus 40-transformed human fibroblasts. Proc Natl Acad Sci USA 77: 7306-7310, 1980.

9 Stern PH and Hoffman RM: Enhanced in vitro selective toxicity of chemotherapeutic agents for human cancer cells based on a metabolic defect. J Natl Cancer Inst 76: 629-639, 1986.

10 Yano S, Li S, Han Q, Tan Y, Bouvet M, Fujiwara T and Hoffman RM: Selective methioninase-induced trap of cancer cells in $S / G_{2}$ phase visualized by FUCCI imaging confers chemosensitivity. Oncotarget 5: 8729-8736, 2014

11 Yano S, Takehara K, Zhao M, Tan Y, Han Q, Li S, Bouvet M, Fujiwara T and Hoffman RM: Tumor-specific cell-cycle decoy by Salmonella typhimurium A1-R combined with tumorselective cell-cycle trap by methioninase overcome tumor intrinsic chemoresistance as visualized by FUCCI imaging. Cell Cycle 15: 1715-1723, 2016.
12 Stern PH and Hoffman RM: Elevated overall rates of transmethylation in cell lines from diverse human tumors. In Vitro 20: 663-670, 1984.

13 Hoffman RM: Is DNA methylation the new guardian of the genome? Mol Cytogenetics 10: 11, 2017.

14 Hoffman RM: The wayward methyl group and the cascade to cancer. Cell Cycle 16: 825-829, 2017.

15 Murakami T, Li S, Han Q, Tan Y, Kiyuna T, Igarashi K, Kawaguchi K, Hwang HK, Miyake K, Singh AS, Nelson SD, Dry SM, Li Y, Hiroshima Y, Lwin TM, DeLong JC, Chishima T, Tanaka K, Bouvet M, Endo I, Eilber FC and Hoffman RM: Recombinant methioninase effectively targets a Ewing's sarcoma in a patient-derived orthotopic xenograft (PDOX) nude-mouse model. Oncotarget 8: 35630-35638, 2017.

16 Lishko VK, Lishko OV and Hoffman RM: Depletion of serum methionine by methioninase in mice. Anticancer Res 13: 14651468, 1993.

17 Tan Y, Xu M, Tan X, Wang X, Saikawa Y, Nagahama T, Sun X, Lenz $M$ and Hoffman RM: Overexpression and large-scale production of recombinant L-methionine-alpha-deaminogammamercaptomethane-lyase for novel anticancer therapy. Protein Expr Purif 9: 233-245, 1997.

18 Tan Y, Sun X, Xu M, Tan X-Z, Sasson A, Rashidi B, Han Q, Tan X-Y, Wang X, An Z, Sun F-X and Hoffman RM: Efficacy of recombinant methioninase in combination with cisplatin on human colon tumors in nude mice. Clin Cancer Res 5: 21572163, 1999.

19 Isakoff MS, Bielack SS, Meltzer $\mathrm{P}$ and Gorlick R: Osteosarcoma: Current treatment and a collaborative pathway to success. J Clin Oncol 33: 3029-3035, 2015. 
20 Bacci G, Ferrari S, Lari S, Mercuri M, Donati D, Longhi A, Forni C, Bertoni F, Versari M and Pignotti E: Osteosarcoma of the limb: amputation or limb salvage in patients treated by neoadjuvant chemotherapy. J Bone Joint Surg Br 84: 88-92, 2002.

21 Muscolo DL, Ayerza MA, Aponte-Tinao LA and Ranalletta M: Partial epiphyseal preservation and intercalary allograft reconstruction in high-grade metaphyseal osteosarcoma of the knee. J Bone Joint Surg Am 86: 2686-2693, 2002.

22 Lewis VO: What's new in musculoskeletal oncology. J Bone Joint Surg Am 89: 1399-1407, 2007.

23 Tome Y, Sugimoto N, Yano S, Momiyama M, Mii S, Maehara H, Bouvet M, Tsuchiya H, Kanaya F and Hoffman RM: Real-time imaging of $\alpha \mathrm{v}$ integrin molecular dynamics in osteosarcoma cells in vitro and in vivo. Anticancer Res 33: 3021-3025, 2013.

24 Tome Y, Tsuchiya H, Hayashi K, Yamauchi K, Sugimoto N, Kanaya $\mathrm{F}$, Tomita $\mathrm{K}$ and Hoffman RM: In vivo gene transfer between interacting human osteosarcoma cell lines is associated with acquisition of enhanced metastatic potential. J Cell Biochem 108: 362-367, 2009.

25 Hayashi K, Zhao M, Yamauchi K, Yamamoto N, Tsuchiya H, Tomita K, Kishimoto H, Bouvet M and Hoffman RM: Systemic targeting of primary bone tumor and lung metastasis of highgrade osteosarcoma in nude mice with a tumor-selective strain of Salmonella typhimurium. Cell Cycle 8: 870-875, 2009.

26 Tome Y, Kimura H, Maehara H, Sugimoto N, Bouvet M, Tsuchiya H, Kanaya F and Hoffman RM: High lung-metastatic variant of human osteosarcoma cells, selected by passage of lung metastasis in nude mice, is associated with increased expression of $\alpha v \beta 3$ integrin. Anticancer Res 33: 3623-3627, 2013.
27 Miwa S, Hiroshima Y, Yano S, Zhang Y, Matsumoto Y, Uehara F, Yamamoto M, Kimura H, Hayashi K, Bouvet M, Tsuchiya H and Hoffman RM: Fluorescence-guided surgery improves outcome in an orthotopic osteosarcoma nude-mouse model. J Orthopaedic Res 32: 1596-1601, 2014.

28 Sugimura T, Birnbaum SM, Winitz $M$ and Greenstein JP: Quantitative nutritional studies with water-soluble, chemically defined diets. VIII: The forced feeding of diets each lacking in one essential amino acid. Arch Biochem Biophys 81: 448-455, 1959.

29 Chello PL and Bertino JR: Dependence of 5-methyltetrahydrofolate utilization by L5178Y murine leukemia cells in vitro on the presence of hydroxycobalamin and transcobalamin II: Cancer Res 33: 1898-1904, 1973.

30 Borriello A and Della Ragione F. The new anticancer era: Tumor metabolism targeting. Cell Cycle 16: 310-311, 2017.
Received June 9, 2017

Revised June 29, 2017

Accepted July 3, 2017 